NATIONAL LABORATORY

MANAGED BY UT-BATTELLE

FOR THE DEPARTMENT OF ENERGY
MSSED

CRADA Final Report
For

CRADA Number NFE-10-02951

The commercial development of water repellent coatings for high voltage transmission lines

Dr. Scott R. Hunter

Oak Ridge National Laboratory

Allan Daniel

Southwire Company

Prepared by

Oak Ridge National Laboratory

Oak Ridge, TN 37831

managed by

UT-BATTELLE, LLC

for the

U.S. Department of Energy

under contract DE-AC05-00OR22725

\section{Scott Hunter}

Digitally signed by Scott Hunter

DN: $\mathrm{cn}=$ Scott Hunter, o, ou,

email=huntersr@ornl.gov, c=US

Date: 2013.10.02 10:01:50
Approved for

Public Release

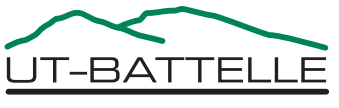




\section{The commercial development of water-repellant coatings for high voltage transmission lines}

\section{Abstract}

The purpose of the Cooperative Research and Development Agreement (CRADA) between UT-Battelle, LLC and Southwire Company was to jointly develop a low cost, commercially viable, water-repellant anti-icing coating system for high voltage transmission lines. Icing of power lines and other structures caused by freezing rain events occurs annually in the United States, and leads to severe and prolonged power outages. These outages cause untold economic and personal distress for many American families and businesses. Researchers at the Department of Energy's Oak Ridge National Laboratory (ORNL) in Oak Ridge, Tennessee have previously developed a set of superhydrophobic coatings with remarkable anti-icing properties that could potentially be sprayed or painted onto hightension power lines and pylons. These coatings drastically reduce ice accumulation on these structures during freezing rain events. The project involved obtaining technical input, supplies and test high voltage cables from Southwire, along with the joint development of anti-icing coating techniques, which would result in a commercial license agreement between Southwire and ORNL, and potentially other companies requiring water repellent anti-icing coatings.

\section{Statement of Objectives}

\section{State of Technology}

New coatings exhibiting superhydrophobic properties have been developed at ORNL using a variety of materials over the past several years, to produce coatings that cause aqueous liquids to "bead up", or be repelled from the surface of a material. Studies, using funds from the DOE Office of Electricity, have shown that these coatings also have remarkable anti-icing properties, drastically reducing the amount of ice accumulation on coated high voltage cables and insulators when subjected to freezing rain conditions in a temperature controlled environmental fog and super cooled rain exposure chamber.

The major obstacles to the immediate deployment of this technology in high voltage electrical transmission applications is the need to improve the coating durability, particularly during cable fabrication, transportation and installation in the field. The jointly funded Southwire-DOE funded project was intended to develop more durable coatings and coating techniques that could be applied in this application.

\section{Problem Statement}

The goals of the CRADA project were as follows:

1) Develop a binder system that would bond the ORNL developed powder-based coatings to aluminum power transmission lines without significantly affecting the superhydrophobic powder's anti-icing properties, and be durable enough to survive the cable fabrication, transportation and installation processes. 
2) Develop a superhydrophobic powder coating application system that could be integrated into Southwire's existing cable fabrication facility.

3) Develop a superhydrophobic powder coating application system that can be used in the field (i.e. on power line cables that have already been deployed).

Southwire expressed considerable interest in licensing the use of the ORNL developed silica based coatings for the anti-icing high voltage power transmission application upon successful completion of these project objectives.

\section{Benefits to the Funding DOE Office's Mission}

The superhydrophobic surfaces and materials developed at ORNL, and commercialized in this project, are unique in that they have the potential for impacting very broad energy generation and conservation sectors, including energy generation, energy transmission, and energy use. These include fuel cells, windmills, coal-fired power plants, steam and hydro turbines, electrical transmission lines, high-power electrical insulators, solar panels, and heat and air conditioning units.

Many of the energy conservation and energy use systems in the industrial and residential sectors can also benefit from the superhydrophobic coating technology. These include heating and cooling systems, building roof coatings, petroleum, chemicals, forest and paper products, iron and steel, cement, and transportation equipment. Most of the energy savings come from three aspects - improved efficiency of current energy generation systems, efficiency improvement of industrial manufacturing systems and electric motors that use $\sim 25 \%$ of the total electric used in the US.

\section{Technical Discussion of Work Performed by All Parties}

The technical objective of the project was to develop a coating system that could be applied to bare overhead distribution and transmission cables, either in the factory before the cables were shipped, or applied as a coating after the cables had been installed on the high voltage power pylons, with the goal that the coatings would help to significantly reduce ice buildup during freezing rain and ice storm events. The project tasks were as follows:

Task 1: (Year 1) - Coat and test sample high voltage cable segments with the ORNL developed anti-icing coatings

1.1 Evaluate existing coating application methods (i.e. spray or paint the coatings directly on the cables during fabrication)

1.2 Explore other application methods (e.g. dip coating, emersion coating techniques during cable fabrication)

1.3 Evaluate different non toxic binder options (e.g. epoxies, paint binders, etc. that would improve the projected life of the coating under actual high UV exposures found in the field)

1.4 Prepare testing protocol for lab samples (e.g. accelerated life testing in corrosive and high UV exposure chambers)

1.5 Prepare testing protocol for cable samples, including accelerated UV exposure, heating and cooling cycles and abrasion resistance 
1.6 Produce and test lab samples

1.7 Produce and test cable sample

Task 2: (Year 2) - Increase the durability of the existing ORNL developed anti-icing coatings

2.1 Explore additional/alternate binder systems (e.g. mechanical binding, flash lamp, thermal plastic resins).

2.2 Explore alternate application systems (e.g. electrostatic powder coating)

2.3 Laboratory testing (same as in Task 1)

2.4 Field testing (look at coating results during and after an ice-storm)

Task 3: (Year 3) - Anti-icing coating product fabrication and scale-up

3.1 Incorporation of "best binder" system into Southwire's manufacturing environment

3.2 Establish quality assurance testing program

3.3 Test quality assurance of coatings/cables

\section{Project Deliverables:}

Aluminum test samples and cable segments were to be provided by Southwire to ORNL for coating and testing. The coated and tested samples and cable segments were then to be shipped back to Southwire for their own evaluation and testing. ORNL was also to provide samples of diatomaceous earth powder that had been functionalized by fluoro based silane self assembled monolayers (SAMs) to make it superhydrophobic. A final report was to be written describing the results and outcomes from the project.

\section{Technical work performed during Year 1 of the project}

Several discussions and technical exchanges were performed between ORNL and Southwire personnel, both at ORNL and at Southwire's development and manufacturing facility in Carrollton, GA. During these exchanges, ORNL researchers provided samples and knowhow on the manufacture, ball milling and functionalization of the superhydrophobic diatomaceous powders to Southwire engineers. These superhydrophobic diatomaceous samples were optimized to provide extreme water repellency by functionalizing the particle surfaces with a fluorosilane agent that produces a very low surface energy coating that not only repels water, but also prevents supercooled water and ice from sticking to the $\mathrm{Al}$ wire cable surfaces, allowing these coating to be used in potentially severe icing conditions.

Additional diatomaceous surface functionalization techniques were developed during the course of this project to improve the durability and adhesion of the superhydrophobic and anti-icing coatings to the underlying $\mathrm{Al}$ and other substrates. A novel double silanation technique was developed where the diatomaceous earth silica particles were partially functionalized by hydrophilic and hydrophobic terminal groups. The hydrophilic terminated groups were attracted to the polymer binder, while the hydrophobic groups repel water as before. This surface treatment results in the diatomaceous earth being much better bound to the polymer matrix, giving a much stronger and more durable coating, while still being extremely water repellent. An ORNL invention disclosure - 
201202928 - resulting partially from these studies was filed on Aug. 8, 2012, titled "Superhydrophobic Coating using Double-Silane Treated Silica Particles" by inventors John Simpson and G. Polyzos.

Spray coating techniques were developed for applying the functionalized diatomaceous earth anti-icing coatings to longer sections of high voltage cables. These coatings were recently tested in an environmental chamber at ORNL, setup to simulate typical ice-storm conditions. The results of the simulated ice storm showed significant ice formation on untreated power cables and only minimal ice formation on the coated cables. Furthermore, the ice that was present on the coated cables was not strongly attached to the cables and easily fell off by tapping the cables.

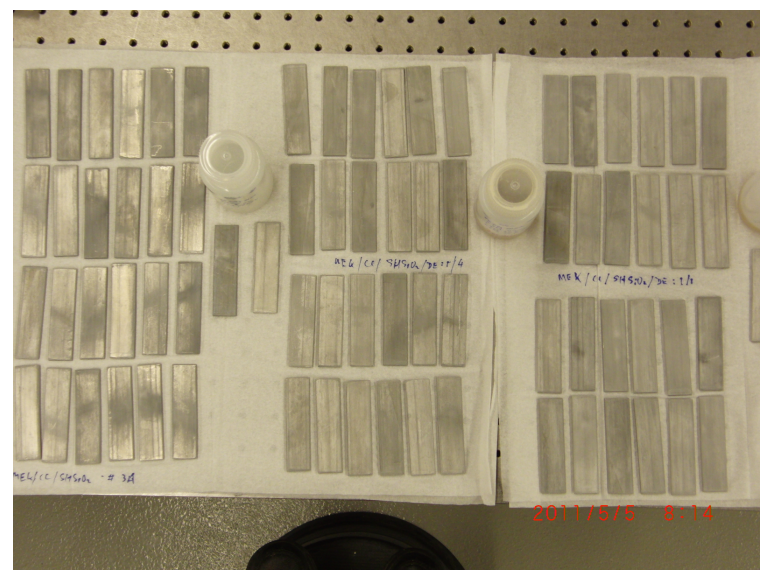

Figure 1. One of the batches of Anti-icing coated Al test samples coated at ORNL and sent to Southwire for testing.



Figure 2. The extremely high contact angles measured for these samples indicates that these samples are extremely water repellent.

As part of this effort, several dozen flattened Al wire segments were coated with various anti-icing formulations developed at ORNL (Figure 1) and found to have extremely high water contact angles (Figure 2) and low rolling angles. These results indicated that the coatings were very water repellent and could be expected to exhibit significant anti-icing properties based on our prior anti-icing studies mentioned above. These first batch test samples were sent to Southwire for evaluation and found to be very water repellent as expected, but not as mechanically durable and UV resistant as needed for this application.

Further studies using more advanced ceramic polymer binders were planned, but were not carried out due to lack of funding. DOE did not provide the expected Year 2 and 3 funding for this CRADA and consequently no further work was done on this very promising project.

\section{Subject Inventions (As defined in the CRADA)}

The project revolved around the ORNL invention disclosures 1768, 1830 and 2370. The patent applications and issued patents are listed below:

- 200601768.0 United States: "Superhydrophobic Powder" Brian R. D’Urso and John T. Simpson Application \#11/777,486 Filed 7/13/2007

- 200601768.2 United States: "Superhydrophobic Powder" 
Brian R. D’Urso and John T. Simpson

Application \#12/273,823 (Continuation in part) Filed 11/19/2008

- 201002370 United States: "Superoleophilic Coatings"

Brian R. D’Urso and John T. Simpson

Application \#12/901,072 Filed 10/8/2010 - will be issued in July 2013

- 200601830 United States: "Flash Bonding Superhydrophobic Powder"

J. Kiggans, C. Blue and John T. Simpson

Patent \#7,754,279

Issued $7 / 13 / 10$

\section{Commercialization Possibilities}

The development of this superhydrophobic technology would, in addition to the uses in the anti-icing applications outlined in this project, benefit many other applications in the residential and commercial building industry, along with totally different applications, including clothing and textiles, automotive applications and scientific instrumentation. The superhydrophobic technology is also directly applicable to many items in the NAIC Code: 325211 Plastics Material and Resin Manufacturing, and can be applied to many polymer and epoxy coated and manufactured items.

According to a Foresight report, the global coatings market is nearing $\$ 100$ billion a year. A new anti-fouling based coating for ships, for example, would result in a $\$ 60 \mathrm{~B}$ savings per year in reduced fuel and coating application costs, where existing anti-fouling coatings typically cost $\$ 150-\$ 350 /$ gal. Aviation de-icing coatings sell for $\$ 5-\$ 7 /$ gal., and cost airlines $\$ 200 \mathrm{M}$ per year to apply in icy environments - a superhydrophobic coating applied to aircraft airfoils could eliminate much of their use.

\section{Plans for Future Collaboration}

Plans for any future collaboration with Southwire on this project are on hold until matching funds can be obtained from the DOE Office of Electricity or other funding agency. Due to reduced funding for high voltage cable reliability issues, the prospects for funding, and hence collaboration, in the near future are minimal. Southwire still has considerable interest in developing anti-icing high voltage cables, but due to the technical risks are unwilling to pursue the required studies without DOE cost sharing.

\section{Conclusions}

During the Year 1 studies, the ORNL-Southwire team performed initial tests on anti-icing coated test cable segments and test structures, and made recommendations on required improvements in coating durability, reduced UV exposure damage and coating manufacturability. Unfortunately due to the lack of DOE funding for the Year 2 and Year 3 efforts, no further work was performed on the project and Southwire did not, as a consequence, provide any matching funding for further development and testing work. 


\section{DOCUMENT AVAILABIUTY}

Reports produced after January 1, 1996, are generally available free via the U.S. Department of Energy (DOE) Information Bridge.

Web site http://www.osti.gov/bridge

Reports produced before January 1, 1996, may be purchased by members of the public from the following source.

National Technical Information Service

5285 Port Royal Road

Springfield, VA 22161

Telephone 703-605-6000 (1-800-553-6847)

TDD 703-487-4639

Fax 703-605-6900

E-mailinfo@ntis.fedworld.gov

Web site http://www.ntis.gov/support/ordernowabout.htm

Reports are available to DOE employees, DOE contractors, Energy Technology Data Exchange (ETDE) representatives, and International Nuclear Information System (INIS)

representatives from the following source.

Office of Scientific and Technical Information

P.O. Box 62

Oak Ridge, TN 37831

Telephone 865-576-8401

Fax 865-576-5728

E-mail reports@adonis.osti.gov

Web site http://www.osti.gov/contact.html

This report was prepared as an account of work sponsored by an agency of the United States Government. Neither the United St ates Government nor any agency thereof, nor any of their employees, makes any warranty, express or implied, or assumes any legal liability or responsibility for the accuracy, completeness, or usefulness of any information, apparatus, product, or process disclosed, or represents that its use would not infringe privately owned rights. Reference herein to any specific commercial product, process, or service by trade name, trademark, manufacturer, or otherwise, does not necessarily constitute or imply its endorsement, recommendation, or favoring by the United States Government or any agency thereof. The views and opinions of authors expressed herein do not necessarily state or reflect those of the United States Government or any agency thereof. 